\title{
Ensuring quality for radical prostatectomies in Canada
}

\author{
Anthony Koupparis, MD; Martin Gleave, MD, FRCSC, FACS
}

See related article on page 13.

Can Urol Assoc J 2010;4(1):26-27

T he number of radical prostatectomies (RP) performed across Canada has increased from 3 per 100000 in 1980/81, to 71 per 100000 in 1998/99. ${ }^{1}$ About 130000 patients are living with or surviving prostate cancer. The number of new cases of prostate cancer across Canada in 2006 was $22480,{ }^{2}$ and the incidence across the provinces is fairly similar. ${ }^{1}$ The current guidelines, although arising from Ontario, have important implications to urological practice nationally.

This guideline makes recommendations on the surgical and pathological aspects of the management of prostate cancer, and supports the multidisciplinary management of prostate cancer. ${ }^{3}$ This approach is not without its critics. ${ }^{4}$ It has been, however, recently shown that over a third of patients undergo a change in treatment or diagnosis with this approach. ${ }^{5}$ It is certainly helpful for more complex cases; dedicated uro-pathological input is invaluable.

There are several surgical aspects covered in these guidelines. The careful consideration suggested for high-risk patients applies equally to low-risk patients, in whom active surveillance should be prioritized. Furthermore, a multimodality approach with primary RP and adjuvant or salvage radiotherapy where appropriate, should be considered for highrisk patients. Recent data ${ }^{6}$ (including our own unpublished data) suggest equivalent or better biochemical progressionfree and cancer-specific survival rates compared to the traditional approach of radiotherapy and androgen deprivation therapy in these patients. High-risk patients undergoing RP also experience comparable morbidity to RP for lower risk disease, in addition to several other benefits. ${ }^{7}$

With regard to pelvic lymph node dissection (PLND), risk-stratification will spare low-risk patients the potential morbidity of PLND. Controversy surrounds the extent of PLND in high-risk patients. The European Association of Urology recommends that all high-risk patients should undergo an extended PLND due to the fact that $15 \%$ to $40 \%$ of patients have positive lymph nodes. However, there is an absence of modern data demonstrating a survival benefit with this approach, therefore standard PLND is adequate in these patients.
In recent years there has been debate on the importance of positive surgical margins (PSM). With the advent of prostate-specific antigen testing and subsequent stage migration of prostate cancer, PSM-rates have fallen. Furthermore, most patients with a PSM do not recur. As a result there is some suggestion that the predictive value of a PSM has decreased. ${ }^{8}$ A PSM is an important surgical outcome which, on univariate and multivariate analysis, is an independent risk factor for biochemical recurrence ${ }^{9}$ and as such should be kept as low as possible. This underlines the importance of detailed uro-pathological assessment of PSMs in terms of location and size, information which is required if subsequent decisions regarding adjuvant or salvage treatments are to be made.

Improvements in surgical technique have meant that the incidence of rectal injury and the need for blood transfusion have fallen over the years. Furthermore a better understanding of the relevant anatomy means that nerve-sparing techniques can and should be offered in appropriate patients. However, constructing guidelines regarding functional outcomes, such as incontinence and erectile dysfunction following RP, is more difficult. Published series vary widely in their rates and have been criticized for not using validated assessment tools pre- and postoperatively. ${ }^{10}$ What is important is the ability to counsel patients regarding their likely functional outcome according to local data.

These are the first published guidelines regarding the surgical and pathological outcomes following RP in Canada, and reinforce what many in the field would consider current best practice. If these guidelines are to ensure quality in the provision of surgery for patients with prostate cancer, the prospective and accurate collection of local departmental outcome data is essential. Many health-care systems have centralized cancer services according an arbitrary minimum volume of patients required to achieve continued competency. Publishing minimum standards for outcome as achieved in the present paper maybe a better method to ensure competency. A difficult issue will be with a centre not achieving the set standards.

From the department of Urologic Sciences, UBC, Vancouver, BC 
Competing Interests: None declared.

This paper has been peer-reviewed.

\section{References}

1. Gibbons L, Waters C. Prostate cancer-testing, incidence, surgery and mortality. Health Rep 2003;14 9-20.

2. Cancer Incidence in Canada. 2009. Statistsics Canada. http://www.statcan.gc.ca/pub/82-231-x/82231-x2008002-eng.pdf. Accessed December 31, 2009.

3. Chin JL, Srigley J, Mayhew LA, et al. Guideline for optimization of surgical and pathological quality performance for radical prostatectomy in prostate cancer management: evidentiary base. Can Urol Assoc I 2010;1:13-25
4. Acher PL, Young AJ, Etherington-Foy R, et al. Improving outcomes in urological cancers: the impact of "multidisciplinary team meetings". Int I Surg 2005;3:121-3.

5. Kurpad R, Kim W, Kim Rathmell W, et al. A multidisciplinary approach to the management of urologic malignancies: Does it influence diagnostic and treatment decisions? Urol Oncol 2009.

6. Loeb S, Schaeffer EM, Trock BJ, et al. What Are the Outcomes of Radical Prostatectomy for High-risk Prostate Cancer? Urology 2009 Nov 19. [Epub ahead of print].

7. Hsu CY, Joniau $S$, Oyen R, et al. Outcome of surgery for clinical unilateral T3a prostate cancer: a singleinstitution experience. Eur Urol 2007;51:121-8; discussion 8-9.

8. Mann $M J$, DeCastro $G J$, Desai $M$, et al. Predictive significance of surgical margin status after prostatectomy for prostate cancer during PSA era. Urology 2008;72:1203-7.

9. Swindle $P$, Eastham JA, Ohori $M$, et al. Do margins matter? The prognostic significance of positive surgical margins in radical prostatectomy specimens. J Urol 2008;179:S47-51.

10. Magheli A, Burnett AL. Erectile dysfunction following prostatectomy: prevention and treatment. Nat Rev Urol 2009;6:415-27.

Correspondence: Dr. Martin Gleave, 2660 0ak Street, Vancouver, BC, V6H 376; fax: 604-8755654; m.gleave@ubc.co

\section{THE starting place for your regional or local meeting}

The CUA Office of Education $(\mathrm{OE})$ is the starting place for your regional or local meeting. We offer members who wish to organize a meeting all our extensive resources:

- the managerial skills to provide you with a full-service meeting planning package

- onsite management and logistical planning

- accreditation at a competitive rate heightened by the fact that members are exempt of taxes on these professional services since they are considered an extension of the CUA
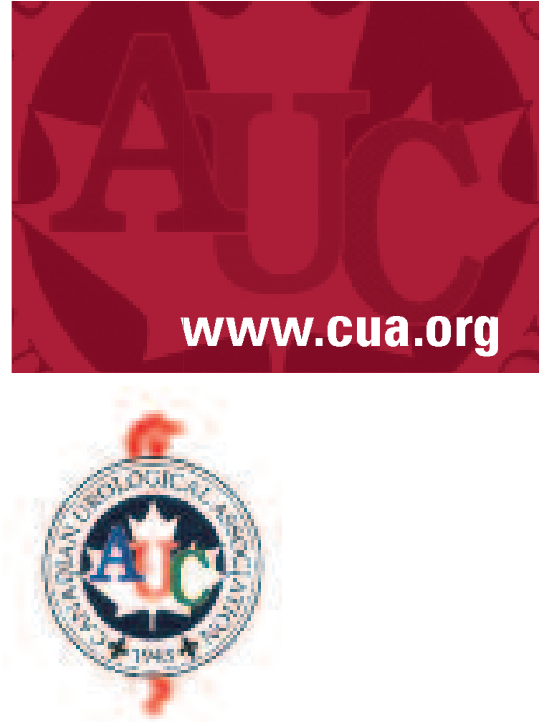

Please contact:

Nadia P. Pace

Project Manager

CUA Office of Education

nadia.pace@cua.org 